\title{
A molecular survey of acute febrile illnesses reveals Plasmodium vivax infections in Kedougou, southeastern Senegal
}

\author{
Makhtar Niang ${ }^{1 *}$, Laty Gaye Thiam 1,2, Abdourahmane Sow ${ }^{3}$, Cheikh Loucoubar ${ }^{3}$, Ndeye Sakha Bob³, \\ Fode Diop ${ }^{1}$, Babacar Diouf ${ }^{1}$, Oumy Niass ${ }^{1}$, Annick Mansourou ${ }^{1}$, Marie Louise Varela ${ }^{1}$, Ronald Perraut ${ }^{1}$, \\ Amadou A Sall ${ }^{3}$ and Aissatou Toure-Balde ${ }^{1}$
}

\begin{abstract}
Background: Control efforts towards malaria due to Plasmodium falciparum significantly decreased the incidence of the disease in many endemic countries including Senegal. Surprisingly, in Kedougou (southeastern Senegal) P. falciparum malaria remains highly prevalent and the relative contribution of other Plasmodium species to the global malaria burden is very poorly documented, partly due to the low sensitivity of routine diagnostic tools. Molecular methods offer better estimate of circulating Plasmodium species in a given area. A molecular survey was carried out to document circulating malaria parasites in Kedougou region.

Methods: A total of 263 long-term stored sera obtained from patients presenting with acute febrile illness in Kedougou between July 2009 and July 2013 were used for malaria parasite determination. Sera were withdrawn from a collection established as part of a surveillance programme of arboviruses infections in the region. Plasmodium species were characterized by a nested PCR-based approach targeting the $18 \mathrm{~S}$ small sub-unit ribosomal RNA genes of Plasmodium spp.

Results: Of the 263 sera screened in this study, Plasmodium genomic DNA was amplifiable by nested PCR from $62.35 \%$ (164/263) of samples. P. falciparum accounted for the majority of infections either as single in $85.97 \%(141 / 164)$ of Plasmodium-positive samples or mixed with Plasmodium ovale $(11.58 \%, 19 / 164)$ or Plasmodium vivax $(1.21 \%, 2 / 164)$. All 19 (11.58\%) P. ovale-infected patients were mixed with P. falciparum, while no Plasmodium malariae was detected in this survey. Four patients (2.43\%) were found to be infected by P. vivax, two of whom were mixed with P. falciparum. P. vivax infections originated from Bandafassi and Ninefesha villages and concerned patients aged 4, 9, 10, and 15 years old, respectively. DNA sequences alignment and phylogenetic analysis demonstrated that sequences from Kedougou corresponded to P. vivax, therefore confirming the presence of P. vivax infections in Senegal.

Conclusion: The results confirm the high prevalence of $P$. falciparum in Kedougou and provide the first molecular evidence of $P$. vivax infections in Senegal. These findings pave the ways for further investigations of $P$. vivax infections in Senegal and its contribution to the global burden of malaria disease before targeted strategies can be deployed.
\end{abstract}

\section{Background}

Malaria is a major infectious disease and remains the main global cause of death in many endemic areas, including Senegal. Success of malaria control

\footnotetext{
*Correspondence: mniang@pasteur.sn

1 Immunology Unit, Pasteur Institute of Dakar, Dakar, Senegal

Full list of author information is available at the end of the article
}

interventions has led to a significant decrease of the disease burden. Between 2000 and 2013 malaria mortality rates decreased by $47 \%$ globally, and by $54 \%$ in sub-Saharan Africa, the region most affected by the disease [1]. Among the five different species of the genus Plasmodium (Plasmodium falciparum, Plasmodium vivax, Plasmodium ovale, Plasmodium malariae, and Plasmodium knowlesi) known to infect humans [2], P. falciparum 
remains the deadliest in Africa [1] and has been the major focus of malaria interventions.

With decreases in the $P$. falciparum burden resulting from successful malaria control interventions [1], attention must be focused on more than 400 million malaria cases due to other parasite species [3]. P. vivax, the most widespread of the Plasmodium species, is fast becoming a recognized cause of different grades of malaria pathologies along with an increasing trend in complicated malaria cases, thus threatening the prospect of malaria elimination in parts of Africa [4-8].

The presence of $P$. vivax malaria in sub-Saharan Africa has been largely neglected based on the demonstrated correlation between the lack of expression of the Duffy blood group in sub-Saharan African population and the absence of $P$. vivax infections $[9,10]$. However recent reports of $P$. vivax infections in Duffy-negative individuals $[7,8,11]$, have called for reconsideration of this widely accepted dogma as they strongly indicate that the Duffy status is no longer a barrier to $P$. vivax infection. Moreover, $P$. vivax appears to be more frequent in countries where either it was not present or it was not detected by the available techniques in the past, as is the case of some countries of West and Central [4, 6-8, 11, 12], becoming therefore a major source of concern.

To date, no $P$. vivax infection has been reported in Senegal despite evidence of its presence in many West African countries [4, 13-15]. A molecular survey of circulating malaria parasites species was carried out on samples collected from acute febrile patients as part of a surveillance programme of arboviruses infections in Kedougou region, southeastern Senegal.

\section{Methods}

\section{Study site}

The study was conducted in the Kedougou region (Figure 1) located in southeast Senegal at the bordering area with Guinea, Mali and Gambia between isohyets 1,200 and $1,300 \mathrm{~mm}$. The climate is Sudano-Guinean with a single rainy season from May to November. The landscape consists of wooded grassland or woodland and dense gallery forest. The fauna is diverse with herbivorous, insectivorous, rodents, and monkeys.

Malaria remains highly prevalent in Kedougou region and transmission is highly seasonal occurring during the rainy season (May-November). In 2014, the Senegalese National Malaria Control Programme reported 25.55\% confirmed clinical malaria cases of which $2.73 \%$ turned into severe disease [16].

\section{Population and study design}

As part of a genetic diversity study of $P$. falciparum isolates in concurrent malaria-arbovirus infections from patients presenting with acute febrile illness (AFI) in Kedougou, a molecular diagnostic was conducted to discriminate $P$. falciparum from other Plasmodium species. This revealed a unique case of $P$. vivax infection in a patient from Ninefesha village. Therefore, additional samples from Ninefesha and nearby villages were retrieved from the sera collection and screened to survey P. vivax infections in Kedougou. A total of 263 sera from patients presenting with AFI between July 2009 and July 2013 in the Kedougou region of Senegal were included in this study. Sera were withdrawn from a collection established as part of a monitoring programme of arboviruses in Kedougou region. AFI was defined as 'any patient older than 1 year with a fever (temperature $>38^{\circ} \mathrm{C}$ ) lasting for less than 2 weeks, exhibiting two or more of the following symptoms: headache, myalgia, eye pain, arthralgia, cough, nausea/vomiting, diarrhoea, jaundice, bleeding and neurological signs'.

\section{Ethical clearance}

The study objectives, benefits and risks were explained in French language or local dialects to all participants before inclusion. Written informed consent was obtained from all adults participants and from the parents, or legal guardians of children. The study was examined and approved by the Senegalese National Health Research Committee.

\section{Molecular detection of Plasmodium species}

The detection of Plasmodium spp. genomic DNA (gDNA) in frozen serum samples has been reported earlier [17, 18]. Genomic DNA isolation of Plasmodium parasites was performed using QIamp DNA Mini Kit (Qiagen, Hilden, Germany) according to manufacturer's instructions. DNA extracted from blood samples of known microscopically confirmed $P$. falciparum, $P$. malariae and $P$. ovale-infected patients were used as positive controls. $P$. vivax gDNA was kindly donated by $\mathrm{Dr}$ Ambroise Ahouidi (Le Dantec Hospital, Dakar).

Qualitative detection of Plasmodium parasite DNA was based on nested PCR with primers targeting the Plasmodium spp. $18 \mathrm{~S}$ small sub-unit ribosomal RNA (18S ssrRNA) gene as described previously [19]. The primary PCR amplification was performed with Plasmodium genus-specific rPLU5 and rPLU6 primers pairs $[20,21]$ and $1.5 \mu$ lof template DNA in a total volume of $25 \mu \mathrm{l}$ using the GoTaq Green Master Mix protocol (Catalogue no M7113, Promega) according to manufacturer's recommendations. The nested reaction was performed for the specific detection of Plasmodium species using previously described primers pairs rFAL1 and rFAL2 for $P$. falciparum, rVIV1 and rVIV2 for $P$. vivax, rOVA1 and rOVA2 for $P$. ovale and rMAL1 and rMAL2 for 


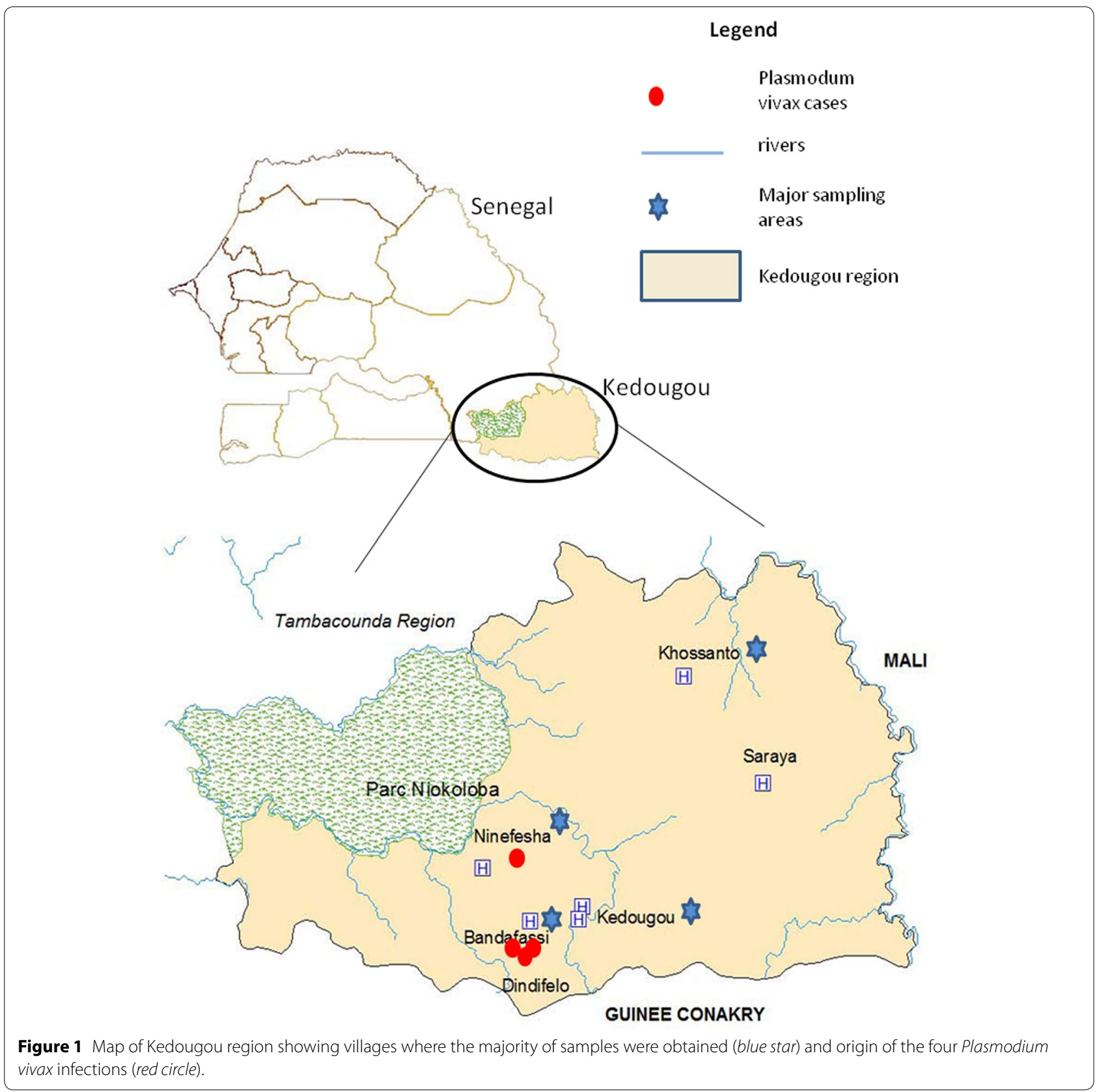

P. malariae $[20,21]$. The genus-specific primary PCR products $(1 \mu \mathrm{l})$ were used as the template in the speciesnested PCR amplification under the same conditions. Nested PCR results were scored as categorical variable (presence vs. absence of amplification). PCR cycling reaction and amplification conditions were as described by Snounou and Singh [19].

Purification of PCR products, DNA sequencing and analysis In order to determine the sequences' identity of the $P$. vivax amplified DNA, the specific bands were extracted from the gel and purified using the QIAquick Gel Extraction Kit as described by the manufacturer (Qiagen ${ }^{\circledR}$ ). The purified PCR products were then sent to COGENICS for sequencing. For each DNA fragment, sequencing was performed from both the $3^{\prime}$ and $5^{\prime}$ directions $(2 \times$ coverage). Consensus sequences were generated from the forward and reverse sequences of each sample and used in a BLASTn algorithm against the Genbank database for similarity profile determination.

Sequence alignment and phylogenic trees were performed using Mega 6.06 software. Plasmodium spp. small 
sub-unit rRNA (SSU RNA) sequences were obtained from Plasmodb version 13.0 and Genbank. Plasmodium vivax: $P$. vivax Sal1_U030779.1, $P$. vivax_HF945443.1, $P$. vivax_HF945441.1; P. falciparum: JQ627152.1; P. ovale: JF894411.1; P. malariae: GU815531.1. Sequences were analysed by the Neighbour Joining method using 100 bootstrap replicates.

\section{Results}

\section{Characteristics of the study population}

A total of 263 sera from patients presenting with AFI enrolled during arboviruses surveillance in Kedougou were screened in this study for the presence of malaria parasite species. Patients were aged one to 65 years old, the majority originated from the village of Bandafassi (Table 1). The mean age of the population varied between 14 years (range 1-65 years) in Bandafassi and 23 years (range 4-60 years) in Kedougou (Table 1). The sex ratio was in favour of females in Bandafassi and in favour of males in others villages (Table 1).

\section{Detection of malaria parasite species in patients by nested PCR}

The four previously diagnosed clinical samples ( $P$. falciparum, $P$. vivax, $P$. malariae, and $P$. ovale) and sterile distilled water were used as the positive and negative controls, respectively to validate the nested PCR approach. The presence of amplified DNA products in a patient's specimen corresponding to $P$. falciparum (205 bp), $P$. vivax (120 bp), P. malariae (144 bp) and P. ovale (375 bp) was confirmed (Figure 2).

Plasmodium genomic DNA was amplifiable by nested PCR from $62.35 \%(164 / 263)$ of the 263 sera screened in this study (Table 2). P. falciparum accounted for the majority of infections and was present either as single infections in $85.97 \%(141 / 164)$ of positive samples or mixed with $P$. ovale $(11.58 \%, 19 / 164)$ or $P$. vivax $(1.21 \%$, $2 / 164)$. Nineteen patients $(11.58 \%)$ were infected with

Table 1 Characteristics of the study population

\begin{tabular}{|c|c|c|c|c|c|}
\hline & Kedougou & Bandafassi & Ninefesha & Other & Total \\
\hline Number & 57 & 149 & 34 & 23 & 263 \\
\hline Percentage (\%) & 21.67 & 56.65 & 12.93 & 8.75 & 100 \\
\hline \multicolumn{6}{|l|}{ Age } \\
\hline Mean & 23 & 14 & 16 & 21 & \\
\hline Range & [4-60] & {$[1-65]$} & {$[1-62]$} & {$[1-50]$} & \\
\hline \multicolumn{6}{|l|}{ Sex } \\
\hline Male & 31 & 73 & 19 & 13 & 136 \\
\hline Female & 26 & 76 & 15 & 10 & 127 \\
\hline $\mathrm{M} / \mathrm{F}$ & 1.19 & 0.96 & 1.26 & 1.3 & \\
\hline
\end{tabular}

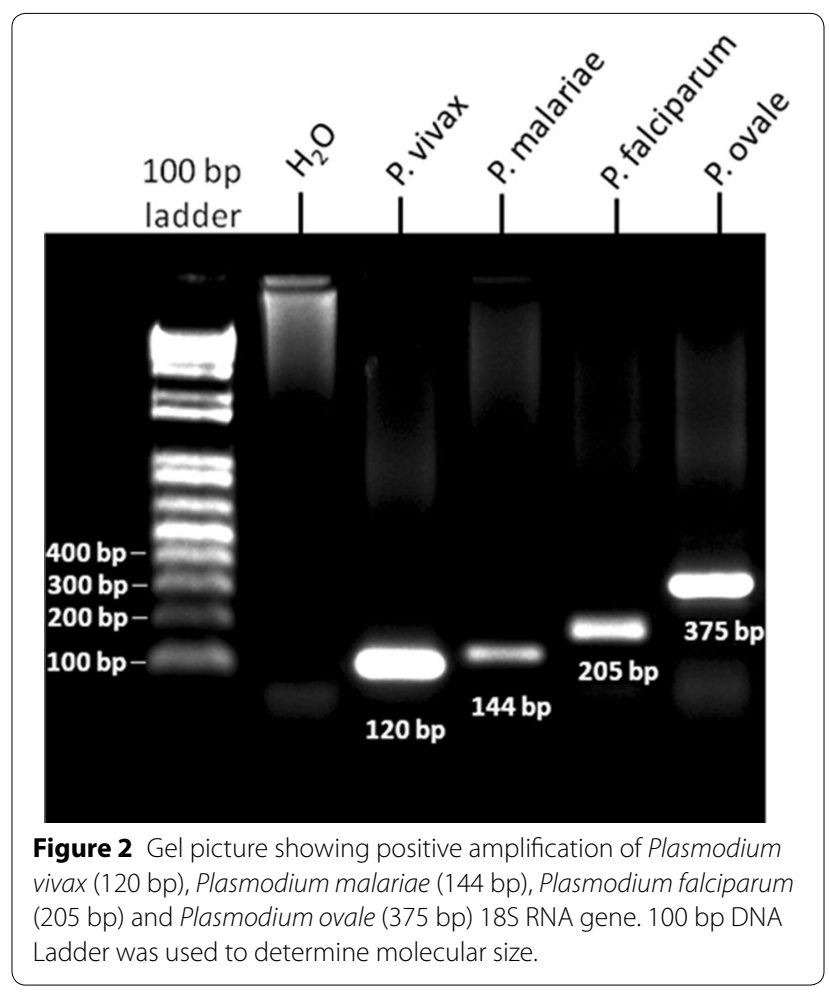

P. ovale, all of which were mixed with $P$. falciparum (Table 2). P. malariae was not detected in the current survey despite report of its presence in Kedougou (Ndiaye et al. unpublished data). Four patients (2.43\%) were found to be infected by $P$. vivax, two of which were mixed infections with $P$. falciparum (Table 2). Three of the four cases of $P$. vivax infections originated from the village of Bandafassi and concerned two females aged 4 and 10 years old and one male aged 15 years. The fourth $P$. vivax case originated from a 9 years old female from Ninefesha village (Table 2).

\section{Sequences analysis confirmation of Plasmodium vivax infections}

To substantiate the PCR assays results on the four incidences of $P$. vivax, DNA sequencing was performed for the four samples for gene specific to $P$. vivax. BLASTn analyses of the DNA sequences generated from the positive $P$. vivax samples confirmed that the $P$. vivax sequences from Kedougou (PVX_KDG1, PVX_KDG2, PVX_KDG3 and PVX_KDG4) matched the Genbank $P$. vivax isolate SV6 $18 \mathrm{~S}$ ribosomal RNA gene partial sequence (ID: JQ627158.1), P. vivax Sal1 blood stage small sub-unit rRNA gene (ID: PVU03079) and P. vivax isolate SV5 18S ribosomal RNA gene partial sequence (ID: JQ627157.1) by 98, 100, 100, and 97\%, respectively (Figure 3). 
Table 2 Details of single and mixed Plasmodium species infections in Kedougou

\begin{tabular}{|c|c|c|c|c|c|c|}
\hline \multirow[t]{2}{*}{ Site (sample size) } & \multicolumn{6}{|c|}{ Plasmodium species } \\
\hline & P. falciparum & P. vivax & P. malariae & P. ovale & P. falciparum $+P$. vivax & P. falciparum $+P$. ovale \\
\hline Kedougou (57) & 42 & 0 & 0 & 0 & 0 & 5 \\
\hline Bandafassi (149) & 77 & 1 & 0 & 0 & 2 & 9 \\
\hline Ninefesha (34) & 4 & 1 & 0 & 0 & 0 & 3 \\
\hline Others (23) & 18 & 0 & 0 & 0 & 0 & 2 \\
\hline Total & 141 & 2 & 0 & 0 & 2 & 19 \\
\hline
\end{tabular}

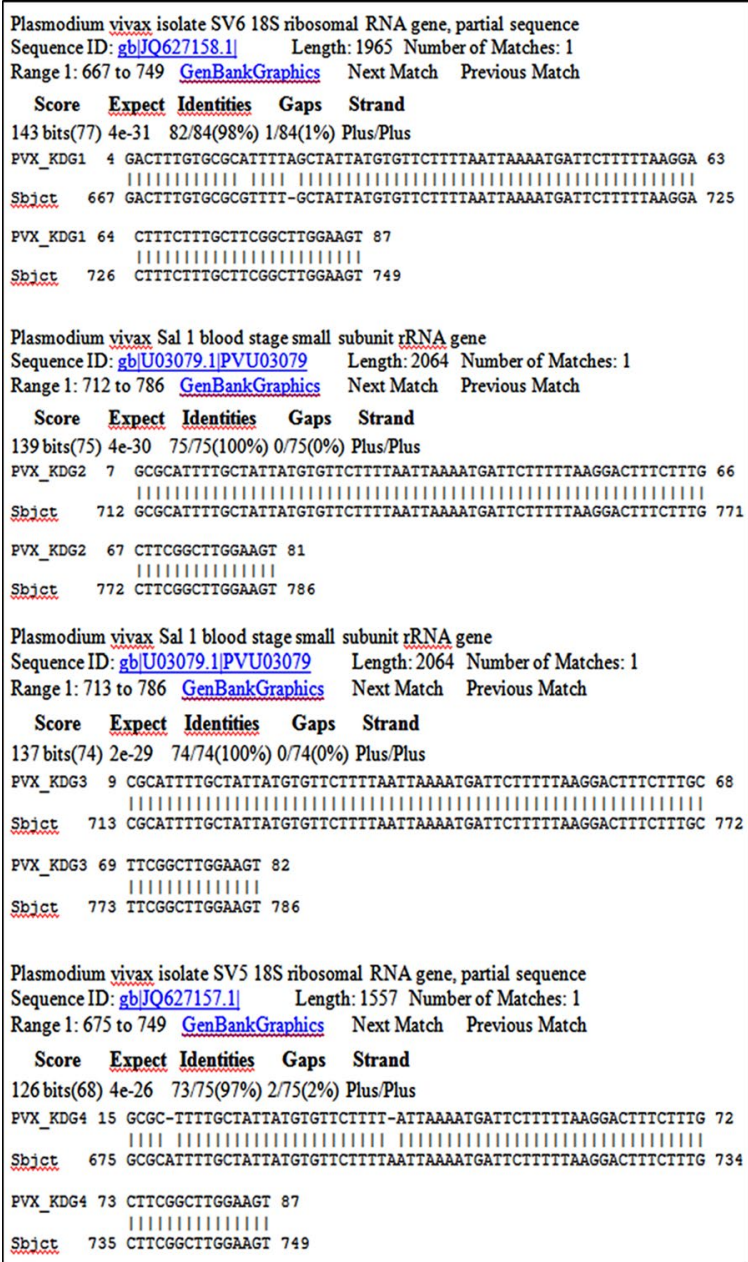

Figure 3 BLASTn output of the sequences generated from the four Plasmodium vivax-infected patients. Each of the sequences was queried against the Plasmodium GenBank data and number of hits with percentages identities displayed.

In addition, multiple sequences alignment of the four DNA sequences from $P$. vivax-infected samples and reference $18 \mathrm{~S}$ rRNA gene sequence of $P$. vivax Sal1 strain indicated perfect homology with limited polymorphism between the Kedougou $P$. vivax DNA sequences and the reference $P$. vivax sequence, therefore demonstrating that sequences from Kedougou corresponded to $P$. vivax (Figure 4).

Consistent with the existence of different small subunit RNA genes in P. vivax [22], phylogenetic analysis showed that sequences from Kedougou cluster with SSU RNA of $P$. vivax genes of different isolates and strains while branching-out from sequences of other Plasmodium spp. (Figure 4). PVX_KDG1 and PVX_KDG4 were closely related to PVX_JQ627158.1 and PVX_JQ627157.1, respectively, while PVX_KDG2 and PVX_KDG3 clustered with PVX-Sal1 reference strain (Figure 5). These observations are in accordance with the sequences analysis data (Figure 3). Taken together, these results confirmed the presence of $P$. vivax infections in Senegal.

\section{Discussion}

The detection of $P$. falciparum and P. vivax DNA from serum samples of microscopically confirmed, malariainfected patients $[17,18]$ has demonstrated the feasibility for retrospective diagnosis of malaria infection in specimen banks of cohort studies, such as in determining malaria co-infection in $\mathrm{HIV}$-seropositive populations or arboviruses-infected patients.

In the present study, nested PCR diagnostic assays targeting the 18S rRNA gene of Plasmodium species has been used to detect malaria parasite DNA in stored sera. The study revealed the predominance of $P$. falciparum either as single or mixed infections with $P$. vivax or $P$. ovale in Kedougou. The fact that all $P$. ovale infections detected in this study were mixed with $P$. falciparum suggests that $P$. ovale infections might be underestimated by microscopy diagnostic. The high prevalence of $P$. falciparum in Kedougou and other regions in Senegal [16] largely justifies the targeted orientation of malaria control strategies against this species. It was surprising that $P$. malariae failed to be detected since studies in different areas of Senegal [23-25], including Kedougou (Ndiaye et al. unpublished data), have documented the presence of P. malariae. The positive amplification obtained with 


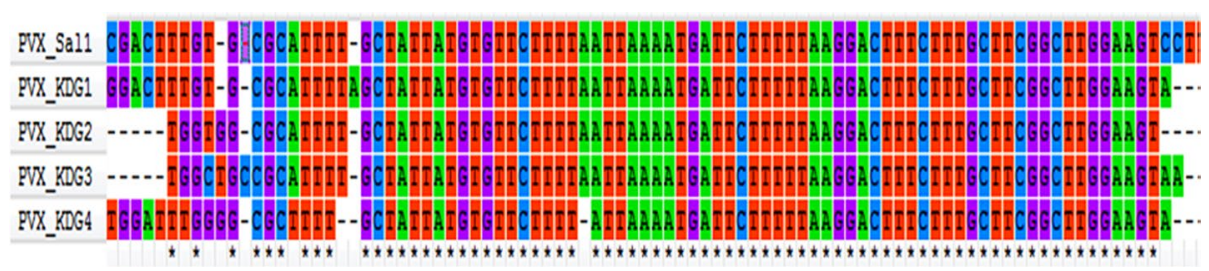

Figure 4 DNA sequence alignment of the four Senegalese Plasmodium vivax isolates with the reference DNA sequence of $P$. vivax SAL-1 strain.

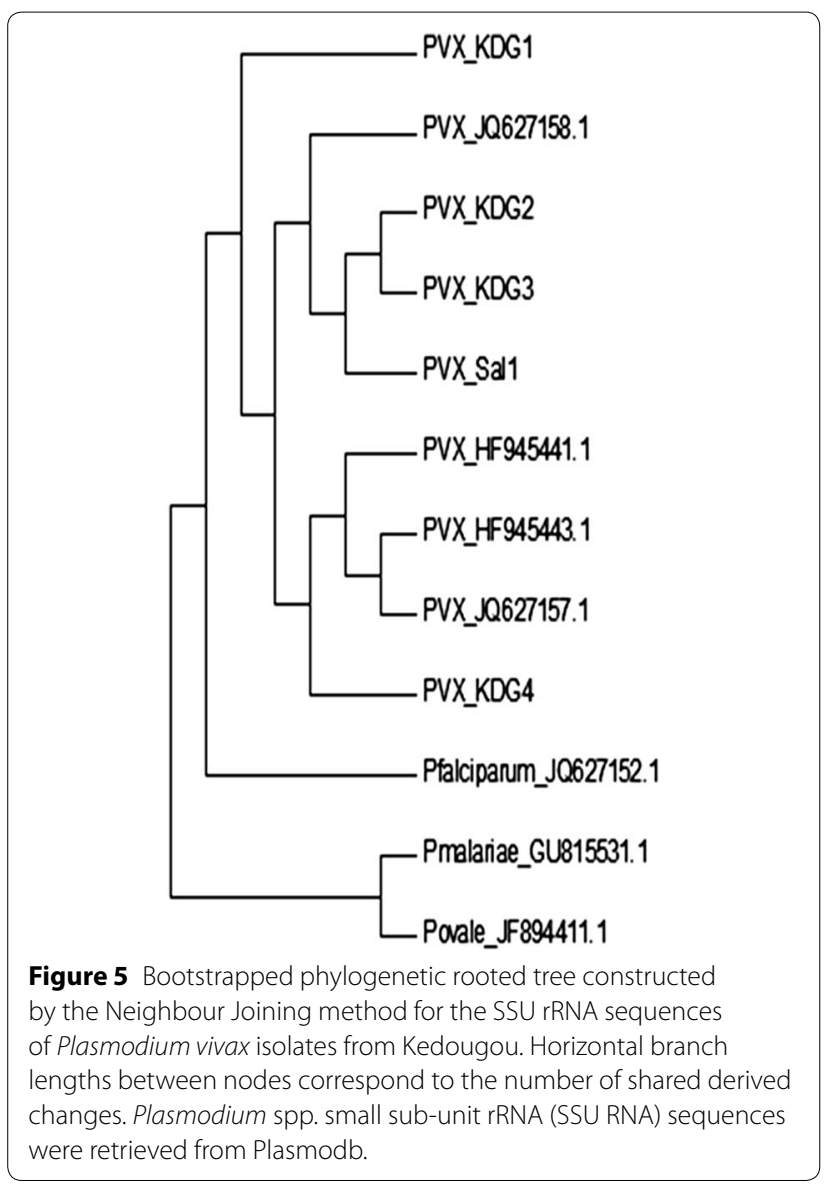

parasite DNA from a microscopy-confirmed P. malariaeinfected patient in the nested PCR approach rules out a technical issue and undoubtedly confirms the absence of $P$. malariae in the screened samples. A possible explanation of the absence of $P$. malariae in the surveyed samples might be a low parasitaemia below the detection limit of the nested PCR approach. Another explanation might be related to the low prevalence of $P$. malariae in the region. Both $P$. ovale and P. malariae have long been reported to be widely distributed in tropical Africa and other major malaria-endemic areas of the world [24, 26-28] and are often associated with $P$. falciparum infections [24, 27] as reported in this study for $P$. ovale.

The present study reports the first substantiated molecular evidence of $P$. vivax infections in patients from Kedougou. There have been other reports of $P$. vivax elsewhere on the African continent where $P$. vivax was initially thought to be absent $[6,7,11,13,14,29]$ due to the high prevalence of Duffy-negative individuals considered resistant to $P$. vivax infection $[10,30]$. However, reports of documented $P$. vivax presence in West and Central African countries such as Congo [29], Cameroun [14, 15] and Mali [13] highly suggest that this parasite is evolving and adapting, becoming therefore a major public health concern. Infections caused by $P$. vivax, initially thought as 'benign' are now gaining higher importance, because of the very wide distribution of $P$. vivax parasite both in tropical and sub-tropical areas [31, 32] and the high number of reported clinical cases [31, 33, 34] along with documented cases of severe $P$. vivax disease and even deaths [35-37]. An important limitation of this study is the inability to link the confirmed $P$. vivax infections with the Duffy phenotypes of the individuals affected, thus the findings reported in the present study deserve to be substantiated by the determination of the Duffy status of the $P$. vivax-infected patients in order to gain insights into the mechanism underlying $P$. vivax infections in Kedougou patients. The inability to link the reported $P$. vivax infections with the disease clinical outcome constitutes an additional limitation of the study. The presence of Duffy-positive ethnic groups that may be present in Senegal, particularly in the Kedougou region, a gold-mining area attracting an important flux of migrants from neighbouring countries, may account for $P$. vivax presence in the area. The recent adaptation of $P$. knowlesi, originally a simian malaria species, to human [2] suggests that a similar adaptation of the $P$. vivax parasite could be occurring, accounting for its increasing prevalence on the African continent.

In recent years, global efforts against malaria have shifted from control to specific strategies aimed at globally eliminating malaria in given areas, implying a need 
for accurate identification of both $P$. falciparum and non $P$. falciparum spp. that might sustain malaria transmission. In Senegal, the National Malaria Control Programme is already struggling to control malaria due to $P$. falciparum; the additional burden of $P$. vivax infections can therefore be daunting.

\section{Conclusion}

The present study provides the first molecular evidence of $P$. vivax infections in Kedougou (southeastern Senegal). Further investigations with a larger sampling in Kedougou and other Senegalese settings are needed to document the presence and prevalence of $P$. vivax infections in Senegal before orientated strategies can be deployed. The results presented here indicate that there may be a need for the National Malaria Control Programme to anticipate reviewing the management of malaria, including $P$. vivax.

\section{Authors' contributions}

MN, AS, CL, AT, and AAS conceived and designed the study. MN, LGT and NSB performed the experiments. MN, LGT, NSB, FD, BD, ON, AM, MLV, and RP participated in data analysis and interpretation. MN, LGT, AS, CL, AAS, and AT wrote the manuscript. All authors read and approved the final manuscript.

\section{Author details \\ ${ }^{1}$ Immunology Unit, Pasteur Institute of Dakar, Dakar, Senegal. ${ }^{2}$ Department of Animal Biology, Cheikh Anta Diop University of de Dakar, Dakar, Senegal. ${ }^{3}$ Arbovirus and Viral Haemorrhagic Fevers Unit, Pasteur Institute of Dakar, Dakar, Senegal.}

\section{Acknowledgements}

The authors would like to express their gratitude to the population, healthcare workers and medical authorities in Kedougou region for their support and cooperation in conducting this study. Joseph Faye and Vincent Richard (Epidemiology Unit, Pasteur Institute of Dakar) are acknowledged for providing the $P$. ovale and P. malariae-positive samples and Ambroise Ahouidi (Le Dantec Hospital of Dakar, Senegal) for the kind donation of P. vivax DNA. The research was supported by the National Institutes of Health (NIH) Grant Number Al1069145.

\section{Compliance with ethical guidelines}

\section{Competing interests}

The authors declare that they have no competing interests.

Received: 26 May 2015 Accepted: 10 July 2015

Published online: 19 July 2015

\section{References}

1. WHO (2015) World malaria report 2014. World Health Organization, Geneva

2. White NJ (2008) Plasmodium knowlesi: the fifth human malaria parasite. Clin Infect Dis 46:172-173

3. Price R, Tjitra E, Guerra C, Yeung S, White NJ, Austey NM (2009) Vivax malaria: neglected and not benign. Am J Trop Med Hyg 77:78-87

4. Abdallah TM, Abdeen MT, Ahmed IS, Hamdan HZ, Magzoub M, Adam I (2013) Severe Plasmodium falciparum and Plasmodium vivax malaria among adults at Kassala Hospital, eastern Sudan. Malar J 12:148

5. Dev N, Gadpayle AK, Sankar J, Choudhary M (2014) An unusual case of heart failure due to Plasmodium vivax infection with a favorable outcome. Rev Soc Bras Med Trop 47:663-665
6. Menard D, Barnadas C, Bouchier C, Henry-Halldin C, Gray LR, Ratsimbasoa A et al (2010) Plasmodium vivax clinical malaria is commonly observed in Duffy-negative Malagasy people. Proc Natl Acad Sci USA 107:5967-5971

7. Mendes C, Dias F, Figueiredo J, Mora VG, Cano J, de Sousa B et al (2011) Duffy negative antigen is no longer a barrier to Plasmodium vivaxmolecular evidences from the African West Coast (Angola and Equatorial Guinea). PLoS Neglect Trop Dis 5:e1192

8. Wurtz N, Mint Lekweiry K, Bogreau H, Pradines B, Rogier C, Ould Mohamed Salem Boukhary A et al (2011) Vivax malaria in Mauritania includes infection of a Duffy-negative individual. Malar J 10:336

9. Miller LH, Carter R (1976) A review. Innate resistance in malaria. Exp Parasitol 40:132-146

10. Miller LH, Mason SJ, Clyde DF, McGinniss MH (1976) The resistance factor to Plasmodium vivax in blacks. The Duffy-blood-group genotype, FyFy. NEJM 295:302-304

11. Ryan JR, Stoute JA, Amon J, Dunton RF, Mtalib R, Koros J et al (2006) Evidence for transmission of Plasmodium vivax among a duffy antigen negative population in Western Kenya. Am J Trop Med Hyg 75:575-581

12. Rubio JM, Benito A, Roche J, Berzosa PJ, Garcia ML, Mico M et al (1999) Semi-nested, multiplex polymerase chain reaction for detection of human malaria parasites and evidence of Plasmodium vivax infection in Equatorial Guinea. Am J Trop Med Hyg 60:183-187

13. Bernabeu M, Gomez-Perez GP, Sissoko S, Niambele MB, Haibala AA, Sanz A et al (2012) Plasmodium vivax malaria in Mali: a study from three different regions. Malar J 11:405

14. Fru-Cho J, Bumah WV, Safeukui I, Nkuo-Akenji T, Titanji VP, Haldar K (2014) Molecular typing reveals substantial Plasmodium vivax infection in asymptomatic adults in a rural area of Cameroon. Malar J 13:170

15. Ngassa Mbenda HG, Das A (2014) Molecular evidence of Plasmodium vivax mono and mixed malaria parasite infections in Duffy-negative native Cameroonians. PLoS One 9:e103262

16. PNLP (2015) Bulletin Epidemiologique Annuel du Paludisme au Senegal. Rapport Programme National de Lutte contre le Paludisme

17. Bharti AR, Patra KP, Chuquiyauri R, Kosek M, Gilman RH, Llanos-Cuentas A et al (2007) Polymerase chain reaction detection of Plasmodium vivax and Plasmodium falciparum DNA from stored serum samples: implications for retrospective diagnosis of malaria. Am J Trop Med Hyg 77:444-446

18. Gal S, Fidler C, Turner S, Lo YM, Roberts DJ, Wainscoat JS (2001) Detection of Plasmodium falciparum DNA in plasma. Ann N Y Acad Sci 945:234-238

19. Snounou G, Singh B (2002) Nested PCR analysis of Plasmodium parasites. Methods Mol Med 72:189-203

20. Snounou G, Viriyakosol S, Jarra W, Thaithong S, Brown KN (1993) Identification of the four human malaria parasite species in field samples by the polymerase chain reaction and detection of a high prevalence of mixed infections. Mol Biochem Parasitol 58:283-292

21. Snounou G, Viriyakosol S, Zhu XP, Jarra W, Pinheiro L, do Rosario VE et al (1993) High sensitivity of detection of human malaria parasites by the use of nested polymerase chain reaction. Mol Biochem Parasitol 61:315-320

22. Muller GC, Beier JC, Traore SF, Toure MB, Traore MM, Bah S et al (2010) Field experiments of Anopheles gambiae attraction to local fruits/seedpods and flowering plants in Mali to optimize strategies for malaria vector control in Africa using attractive toxic sugar bait methods. Malar J 9:262

23. Konate L, Diagne N, Brahimi K, Faye O, Legros F, Rogier C et al (1994) Biology of the vectors and transmission of Plasmodium falciparum, P. malariae and $P$. ovale in a village in the savanna of west Africa (Dielmo, Senegal). Parasite 1:325-333

24. Roucher C, Rogier C, Sokhna C, Tall A, Trape JF (2014) A 20-year longitudinal study of Plasmodium ovale and Plasmodium malariae prevalence and morbidity in a West African population. PLoS One 9:e87169

25. Trape JF, Tall A, Sokhna C, Ly AB, Diagne N, Ndiath O et al (2014) The rise and fall of malaria in a West African rural community, Dielmo, Senegal, from 1990 to 2012: a 22 year longitudinal study. Lancet Infect Dis $14: 476-488$

26. Kang Y, Yang J (2013) A case of Plasmodium ovale malaria imported from West Africa. Korean J Parasitol 51:213-218

27. Ouldabdallahi M, Ouldbezeid M, Lemrabot MA, Ouldelvally A, Ouldkhairi ML, Dialw B et al (2015) [Study of morbidity and Plasmodium species in the several geographic-climatic areas of Mauritania] (in French). Bull Soc Pathol Exot 108:112-116 
28. Zhou X, Huang JL, Njuabe MT, Li SG, Chen JH, Zhou XN (2014) A molecular survey of febrile cases in malaria-endemic areas along China-Myanmar border in Yunnan province, People's Republic of China. Parasite 21:27

29. Fukuda MM, Klein TA, Kochel T, Quandelacy TM, Smith BL, Villinski J et al (2011) Malaria and other vector-borne infection surveillance in the U.S. Department of Defense Armed Forces Health Surveillance Center-Global Emerging Infections Surveillance program: review of 2009 accomplishments. BMC Public Health 11(Suppl 2):S9

30. Menard D, Andriantsoanirina V, Khim N, Ratsimbasoa A, Witkowski B, Benedet C et al (2013) Global analysis of Plasmodium falciparum $\mathrm{Na}(+) / \mathrm{H}(+)$ exchanger (pfnhe-1) allele polymorphism and its usefulness as a marker of in vitro resistance to quinine. Int J Parasitol Drugs Drug Resist 3:8-19

31. Amaratunga C, Witkowski B, Khim N, Menard D, Fairhurst RM (2014) Artemisinin resistance in Plasmodium falciparum. Lancet Infect Dis 14:449-450

32. Mac-Daniel L, Buckwalter MR, Berthet M, Virk Y, Yui K, Albert ML et al (2014) Local immune response to injection of Plasmodium sporozoites into the skin. J Immunol 193:1246-1257
33. Price RN, Douglas NM, Anstey NM (2009) New developments in Plasmodium vivax malaria: severe disease and the rise of chloroquine resistance. Curr Opin Infect Dis 22:430-435

34. Ariey F, Witkowski B, Amaratunga C, Beghain J, Langlois AC, Khim N et al (2014) A molecular marker of artemisinin-resistant Plasmodium falciparum malaria. Nature 505:50-55

35. Picot S, Olliaro P, de Monbrison F, Bienvenu AL, Price RN, Ringwald P (2009) A systematic review and meta-analysis of evidence for correlation between molecular markers of parasite resistance and treatment outcome in falciparum malaria. Malar J 8:89

36. Anstey NM, Russell B, Yeo TW, Price RN (2009) The pathophysiology of vivax malaria. Trends Parasitol 25:220-227

37. Price RN, Dorsey G, Nosten F (2009) Antimalarial therapies in children from Papua New Guinea. NEJM 360:1254 (author reply 1255)

\section{Submit your next manuscript to BioMed Central and take full advantage of:}

- Convenient online submission

- Thorough peer review

- No space constraints or color figure charges

- Immediate publication on acceptance

- Inclusion in PubMed, CAS, Scopus and Google Scholar

- Research which is freely available for redistribution

Submit your manuscript at

www.biomedcentral.com/submit

C Biomed Central 